\title{
Discrepancies of Serum Creatinine Levels among CKDu Patients in Kebithigollawa, Sri Lanka: Retrospective Study
}

\author{
A.R.N. Silva ${ }^{a *}$, K.L.K.T.D. Sandharenu ${ }^{b}$, R.S.P. Fernando ${ }^{c}$, H.E.H. Perera ${ }^{a}$, \\ R.S. Maddumage ${ }^{\mathrm{a}}$ \\ nsrajith2005@yahoo.com \\ ${ }^{a}$ Department of Basic Sciences, Faculty of Allied Health Sciences, General Sir John Kotelawala Defence \\ University, Ratmalana, 10380, Sri Lanka. \\ ${ }^{b}$ Department of Nursing and Midwifery, Faculty of Allied Health Sciences, General Sir John Kotelawala \\ Defence University, Ratmalana,10380, Sri Lanka. \\ ${ }^{c}$ Department of Physiotherapy, Faculty of Allied Health Sciences, General Sir John Kotelawala Defence \\ University, Ratmalana, 10380, Sri Lanka.
}

\begin{abstract}
Chronic kidney disease of uncertain etiology (CKDu) in Sri Lanka has become a major health issue. It is characterized by lacking a causal association with risk factors such as diabetes, urinary tract infection and hypertension while the diagnosis is based on kidney dysfunction markers including creatinine in blood or urine, with derived indices such as eGFR. The study presumed that creatinine levels may show seasonal variation so that its dependability should need assessment. Data were collected from volunteers $(n=17)$ selected from about one hundred patients of CKDu at Ayruveda therapeutic clinic of Kebithigollawa which is in the north central province, the most affected in the country. The selection criteria included the availability of investigation records spanning creatinine, protein, and albumin as well as Calcium levels in serum over last three years with concurrent occupation in paddy farming. Results showed fluctuations in serum creatinine levels with a seasonal trend. Individual comparison of creatinine levels indicated a general tendency of having peak values in the periods between February \& April and again in July \& August which coincide with Maha and Yala paddy cultivations respectively. Additionally, mean creatinine levels over the duration either increased $(n=7)$ or decreased $(n=5)$ by 31 and $24 \%$ respectively perhaps due to self-care differences. Other parameters did not show noticeable trends during the period. In summary, variations of serum creatinine levels may occur in CKDu-diagnosed people coinciding with the seasons of paddy cultivation.
\end{abstract}

Keywords: Chronic kidney disease of uncertain etiology; Serum creatinine level; Paddy farming 


\section{Introduction}

Chronic kidney disease (CKD) is a condition that can be defined as the gradual loss of renal function over prolong period. CKD is a major public health issue in many parts of the world, where the incidence continues to rise. A serious health issue which could eventually led to end-stage renal disease (ESRD) and increased cardiovascular morbidity and mortality is chronic kidney disease. CKD affects 10-16 percent of adults around the world, according to the records of various countries, including the United States. The incidence of CKD within the Turkish population is 15.7 percent [1]. The high cost involved in the management of end stage renal failure has led to a substantial burden on global health-care resources. The management of CKD is even more difficult in developing countries due to lack of resources and restrictions in health care spending. Since 1990 large and a growing number of people suffer from CKDu in Sri Lanka. It mainly occurs in North central, North western, Eastern and Uva provinces of the country. According to the WHO, more than 20000 deaths have been reported in past 20years, up to 2015[2]. WHO community-based screening study reported that both males and females are affected with a male majority. Majority of patients were from low-income agriculture community who had been involved in paddy farming practices for five years or longer in the country's dry zone [3]. Sri Lankan CKDu patients show a male majority. The patients are most commonly from 30 to 60 years of age [4]. Since the outbreak of the disease, in Sri Lanka the cause of CKDu has been under investigation by researchers. Many hypotheses based on environmental causal factors have come up without however a finality as link to other possibilities such as genetic predisposition is apparent. Certainly, CKDu shows clustering based on family links and history [5]. Another hypothesis is contaminated drinking water from shallow dug wells. Dug-well water level depends on the recharge of water table by extensive irrigation canals and man=made reservoir system in the zone and it remains vulnerable for anthropogenic contamination [6, 7]. Most leading hypotheses for CKDu of Sri Lanka are agrochemicals such as fertilizer and pesticide amid farmers in endemic area tend to overuse agrochemicals with poor safety measures. This may have increase the CKDu risk [8.9]. According to the previous studies, there is a connection between pesticide exposure and CKDu risk [10]. Jayasumana et al. (2015) suggested glyphosate, a widely used herbicide agrochemical, forming complexes with metals could be responsible for CKDu in Sri Lanka. Hence, hard water in endemic area may form solid complexes of magnesium, calcium, and arsenic with glyphosate that are highly insoluble and poorly absorbed [11]. Studies says that higher urinary glyphosate and heavy metal excretion was shown in both, with CKDu and healthy controls in endemic areas [12]. In 2008, Bandara et al. reported higher concentration of $\mathrm{Cd}$ in the reservoir water used by $\mathrm{CKDu}$ affected families in endemic areas [13]. Imported agrochemicals and fertilizers in Sri Lanka can be contaminated by arsenic [14]. Chandrajith et al. (2011) suggested that the cytotoxic properties of fluoride is enhanced by hard water, where undeniably, fluoride levels in drinking water are above WHO safe levels CKDu endemic area $[15,16]$. The causative factors and etiology of this chronic kidney disease therefore is still considered uncertain or unknown and abbreviated as CKDu with recommendations of the National Research Programme for CKD of the Ministry of Health in Sri Lanka [17]. 


\section{Materials and Methods}

According to the World Health Organization, approximately $15 \%$ of the populations in Anuradhapura, Polonnaruwa districts, in the age group between 15-70 years are affected by CKDu. Although the majority of those affected are male paddy farmers and agricultural labourers, there are now a growing number of women and children being affected by CKDu. Hence data were collected from the patients attending Ayurveda clinic, Kabithigollawa. The collected data includes investigation reports (Serum creatinine (S. Cr), eGFR, HB, etc.), clinical and related social history. Hundreds of patients who had attended the above-mentioned clinic on the selected day were interviewed. Only seventeen patients were eligible for this study depending on the availability of investigation reports related to their disease history. From the above seventeen patients, twelve paddy farmers were selected for this study.

\section{Results}

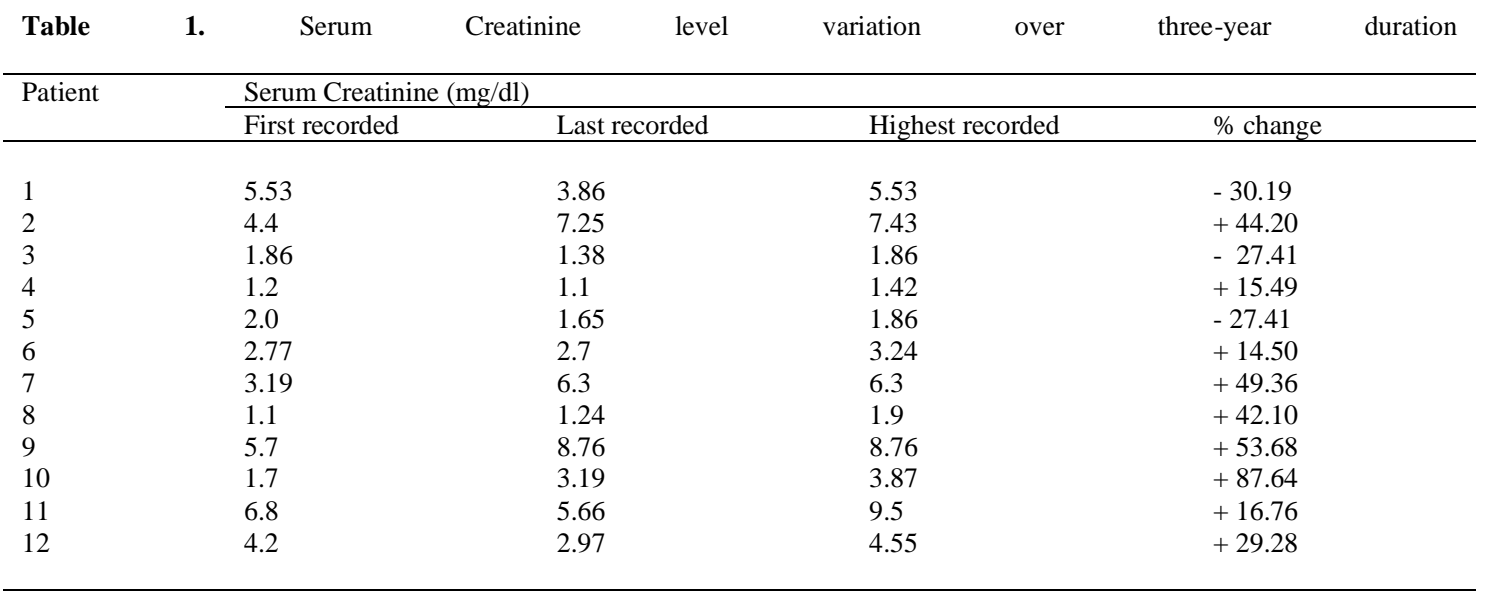

+ or -, increase or decrease compared to the first recorded, respectively. 


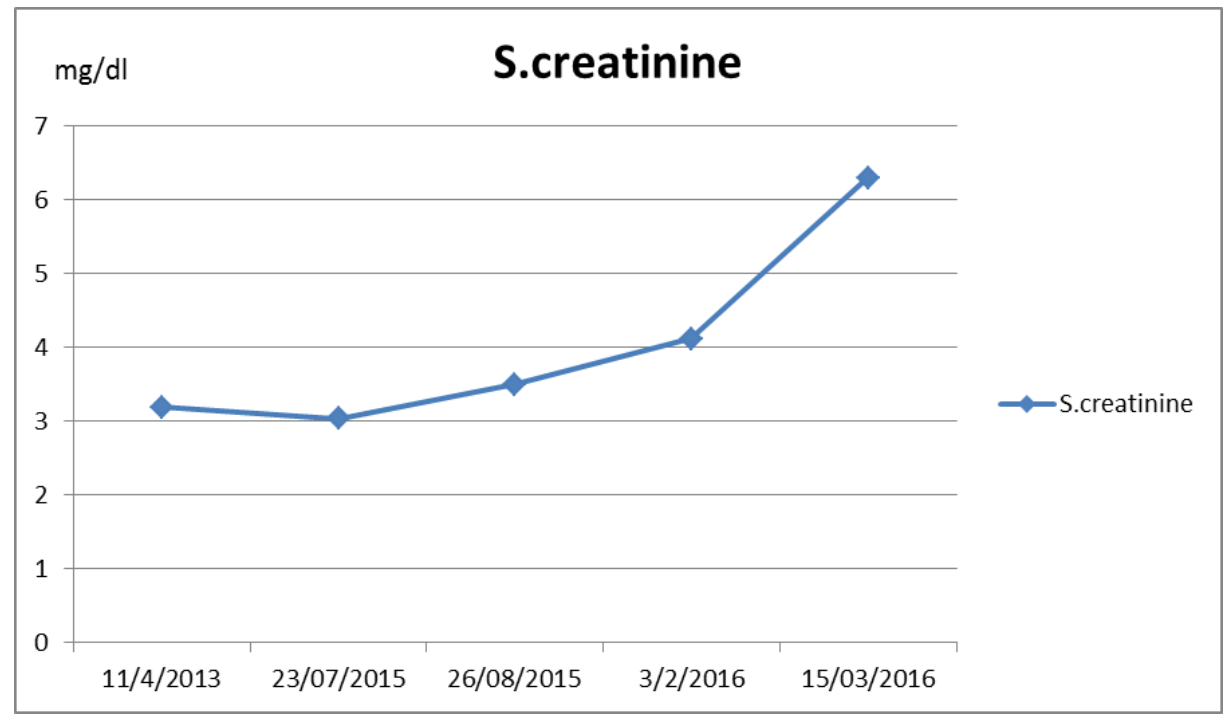

Fig. 1. Patient 07; Serum Creatinine level variation over years

Patient 7 was diagnosed to have CKDu on $11^{\text {th }}$ of April 2013 with a S. Cr level of $3.19 \mathrm{mg} / \mathrm{dl}$. He stopped paddy farming due to the disease for some period \& it led to a decrease in his $\mathrm{S}$. Cr level to $3.04 \mathrm{mg} / \mathrm{dl}$ on $23^{\text {rd }}$ of July 2015. He restarted paddy farming since "Maha" season of 2015. Following that, his blood levels of creatinine increased gradually to a maximum of $6.3 \mathrm{mg} / \mathrm{dl}$ noted on $15^{\text {th }}$ March 2016.

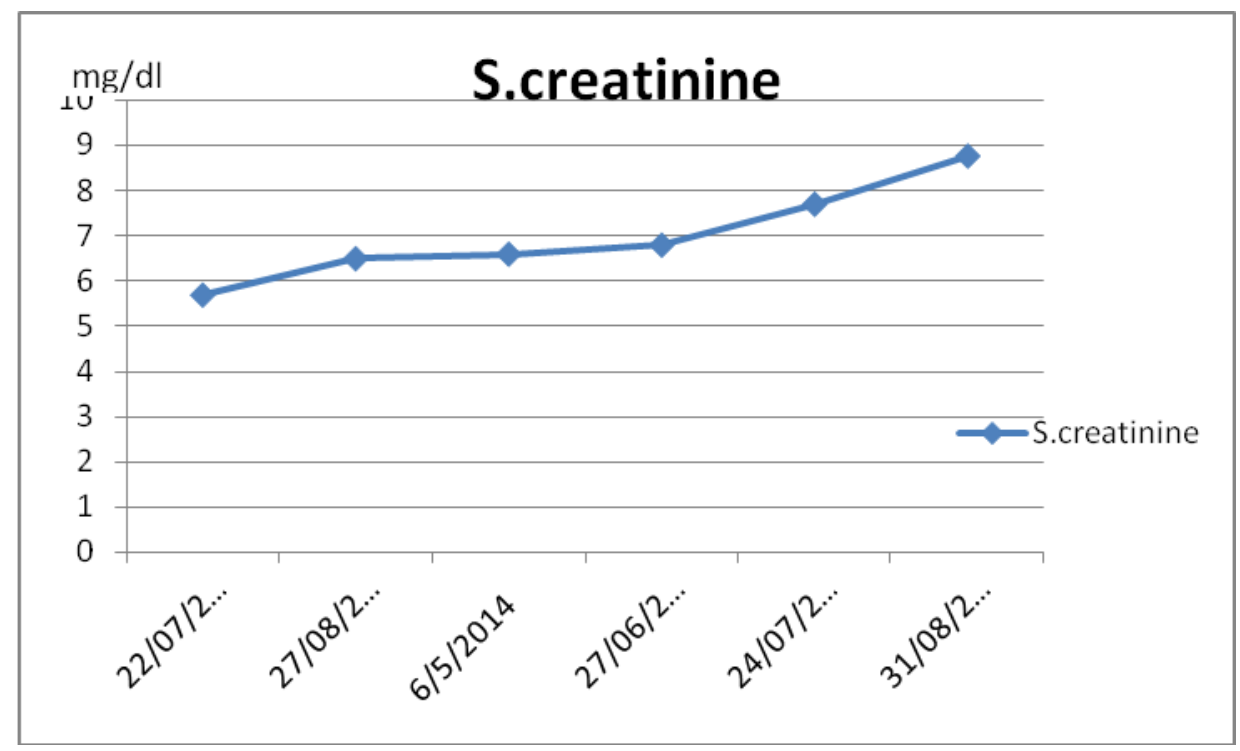

Fig. 2. Patient 09; Serum creatinine level variation. 
Patient 9 was diagnosed to have CKDu on $22^{\text {nd }}$ of July 2013 with a S. Cr of $5.7 \mathrm{mg} / \mathrm{dl}$. He continued paddy farming in "Maha" season of the year. His S. Cr level gradually increased to a level of $8.76 \mathrm{mg} / \mathrm{dl}$, noted on $31^{\text {st }}$ of August 2015 .

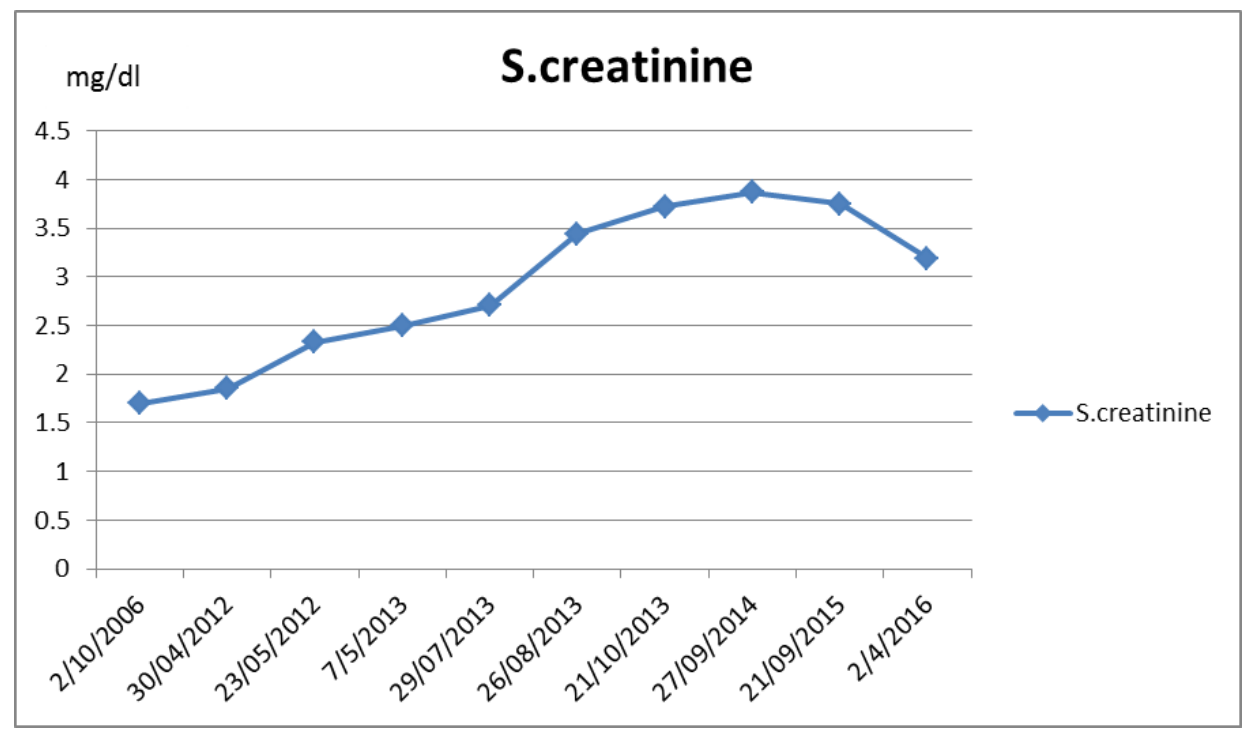

Fig. 3. Patient 10; Serum creatinine level variation.

Patient 10 was diagnosed to have CKDu on $2^{\text {nd }}$ of October 2006 with a S. Cr level of $1.7 \mathrm{mg} / \mathrm{dl}$. Following the disease diagnosis, he stopped paddy farming for 6 years period. Since the harvesting season of "Yala", 2012 , he restarted paddy farming. There after he continued paddy farming in both "Yala" and "Maha" seasons until 2014. His blood level of creatinine increased in this period, to $3.87 \mathrm{mg} / \mathrm{dl}$, noted on $27^{\text {th }}$ September 2014 . Then he stopped paddy farming completely, and it led to decrease his $\mathrm{S}$. Cr level to a value of $3.19 \mathrm{mg} / \mathrm{dl}$, noted on $25^{\text {th }}$ April 2016.

\section{Discussion}

The study area of Kabithigollawa selected as the most appropriate area for this study, as more than $95 \%$ of its population are paddy farmers. According to the previous studies related to CKDu in this area, more than $15 \%$ of the paddy farmers were affected by CKDu. The farmers in this region are cultivating paddy in two seasons, called "Yala" and "Maha". "Yala" is the period of end October to end March. "Maha" is the period of June to August. In both of these seasons, during the first two months, the preparation of paddy field and plantation of paddy is done. The harvesting is done in last month. In those time period, the farmers do not have enough time and facilities to take their meals properly and to drink adequate water. As this area contains a very sunny weather during this period, loss of water from their bodies as sweat is very high. During the harvesting time, the temperature of this area rises to the peak, so the situation becomes crucial.

Creatinine is a waste product, which is produced by muscle cells during their activity, and it is excreted via kidneys. When the kidneys are not properly functioning, as in CKDu patients, creatinine cannot be excreted 
properly, and its blood level rises. The condition aggravates in farmers as their water intake is low and loss of water as sweat is very high due to the weather condition. It leads to very high S. Cr levels in their blood.

Patient 7 and 9 have been identified as CKDu patients, but they are still continuing their career as paddy farmers. The figure 1 and 2 shows the S. Cr. Levels variation of patient 7 and 9, respectively. According to those charts, it can be pointed that, their S. Cr levels rise to peak during Yala and Maha seasons and lowers during the other periods over couples of years. When patient 10 is considered, after being identified as a CKDu patient, he stopped paddy cultivation, but after a short period of time due to the economic problems, he had to restart paddy cultivation. As his S. Cr level lowers with stopping paddy cultivation \& re-rises with restarting of cultivation, he was advised by the hospital clinic to stop paddy farming again. It leads to lower the level of his $\mathrm{S}$. Cr again. This is showed in figure 3.

According to the study, among the patients attending the clinic, $70 \%$ are continuing their agricultural works. During the three years period 55\% fluctuations of serum creatinine levels (mean) were noticed including $31 \%$ increased and $24 \%$ decreased between on diagnosis and most recent value. Peak values of serum creatinine in between the above were individually considered for further analysis. According to the analysis the highest levels of creatinine were reported in the period of February to April and July to August. Slow progression of the disease was also noticed with the patients who does not involved in agricultural activities after getting the disease. Other Biochemical parameter does not show any noticeable difference during three years period. The first peak of serum creatinine levels was reported in February to March period where the harvesting period of the "Maha" season. The second peak was reported in July to August seeing that the dry season of the year.

\section{Conclusion}

According to the study, there is a possibility of changing the serum creatinine levels of the patients, according to their seasonal behavior. In addition to that, by several studies conducted globally, a number of environmental risk factors has been recognized as probable causes of CKD, namely exposure to heavy metals (arsenic, cadmium, lead, mercury, and chromium), agrochemicals, and nephrotoxic substances. Furthermore, non-steroidal anti-inflammatory drugs (NSAIDs), e.g. aspirin, and the infectious diseases like malaria, leptospirosis, Hantavirus, and leprosy also can lead to CKD [18]. It is needed to investigate and study more, to prove that population's seasonal behavior act as a critical factor leading to CKD. The second peak was reported in July to August seeing that the dry season of the year.

As seasonal variations of serum creatinine levels were noticed in the current study, further studies needed to be conducted, to identify the reasons for these variations. Proper self-management of the disease should be implemented to maintain the quality of life of CKDu patients. 


\section{Acknowledgements}

We would like to express our heartiest gratitude to General Sir John Kotelawala Defence University, Sri Lanka for the support provided in all aspects.

\section{References}

1. Coresh, J., Selvin, E., Stevens, L.A., Manzi, J., Kusek, J.W., Eggers, P., Van Lente, F. and Levey, A.S., 2007. Prevalence of chronic kidney disease in the United States, Jama 298(17), pp. 2038-2047.

2. Annual Health Bulletin-Sri Lanka Ministry of Health Medical Statistics Unit; $2012 . \quad$ Availableat: http://www.health.gov.lk/enWeb/publication/AHB- Accessed December 20, 2016.

3. Jayatilake, N., Mendis, S., Maheepala, P. and Mehta, F.R., 2013. Chronic kidney disease of uncertain aetiology: prevalence and causative factors in a developing country, BMC nephrology 14(1), pp. 1-13.

4. Nanayakkara, S., Stmld, S., Abeysekera, T., Chandrajith, R., Ratnatunga, N., Edl, G., Yan, J., Hitomi, T., Muso, E., Komiya, T. and Harada, K.H., 2013. An integrative study of the genetic, social and environmental determinants of chronic kidney disease characterized by tubulointerstitial damages in the North Central Region of Sri Lanka, Journal of occupational health, pp. 13-0172.

5. Jayasekara, J.M., Dissanayake, D.M., Adhikari, S.B., 2013. Geographical distribution of chronic kidney disease of unknown origin in North Central Region of Sri Lanka, Ceylon Med J, pp. 6-10.

6. Nanayakkara, S., Stmld, S., Abeysekera, T., Chandrajith, R., Ratnatunga, N., Edl, G., Yan, J., Hitomi, T., Muso, E., Komiya, T. and Harada, K.H., 2013. An integrative study of the genetic, social and environmental determinants of chronic kidney disease characterized by tubulointerstitial damages in the North Central Region of Sri Lanka, Journal of occupational health, pp. 13-0172.

7. Siriwardhana, E.A.R.I.E., Perera, P.A.J., Sivakanesan, R., Abeysekara, T., Nugegoda, D.B. and Jayaweera, J.A.A.S., 2015. Dehydration and malaria augment the risk of developing chronic kidney disease in Sri Lanka, Indian journal of nephrology 25(3), p. 146.

8. Jayasumana, C., Orantes, C., Herrera, R., Almaguer, M., Lopez, L., Silva, L.C., Ordunez, P., Siribaddana, S., Gunatilake, S. and De Broe, M.E., 2017. Chronic interstitial nephritis in agricultural communities: a worldwide epidemic with social, occupational and environmental determinants, Nephrology Dialysis Transplantation, 32(2), pp. 234-241.

9. Peiris-John, R., Wanigasuriya, J.K.P., Wickremasinghe, A.R., Dissanayake, W.P. and Hittarage, A., 2006. Exposure to acetylcholinesterase-inhibiting pesticides and chronic renal failure.

10. Dharma-Wardana, M.W.C., Amarasiri, S.L., Dharmawardene, N. and Panabokke, C.R., 2015. Chronic kidney disease of unknown aetiology and ground-water ionicity: study based on Sri Lanka, Environmental geochemistry and health 37(2), pp. 221-231.

11. Jayasumana, C., Gunatilake, S., Siribaddana, S., 2015. Simultaneous exposure to multiple heavy metals and glyphosate may contribute to Sri Lankan agricultural nephropathy, BMC nephrology 16(1), pp. 1-8.

12. Bandara, J.M.R.S., Senevirathna, D.M.A.N., Dasanayake, D.M.R.S.B., Herath, V., Bandara, J.M.R.P., Abeysekara, T. and Rajapaksha, K.H., 2008. Chronic renal failure among farm families in cascade irrigation systems in Sri Lanka associated with elevated dietary cadmium levels in rice and freshwater fish (Tilapia), Environmental Geochemistry and Health 30(5), pp. 465478 .

13. Jayasumana, C., Fonseka, S., Fernando, A., Jayalath, K., Amarasinghe, M., Siribaddana, S., Gunatilake, S. and Paranagama, P., 2015. Phosphate fertilizer is a main source of arsenic in areas affected with chronic kidney disease of unknown etiology in Sri Lanka, SpringerPlus 4(1), pp. 1-8.

14. Chandrajith, R., Dissanayake, C.B., Ariyarathna, T., Herath, H.M.J.M.K., Padmasiri, J.P., 2011. Dose-dependent Na and Ca in fluoride-rich drinking water-another major cause of chronic renal failure in tropical arid regions, Science of the total environment, 409(4), pp. 671-675.

15. Chandrajith, R., Dissanayake, C.B., Ariyarathna, T., Herath, H.M.J.M.K. and Padmasiri, J.P., 2011. Dose-dependent Na and $\mathrm{Ca}$ in fluoride-rich drinking water-another major cause of chronic renal failure in tropical arid regions, Science of the total environment 409(4), pp. 671-675. 
16. Redmon, J.H., Elledge, M.F., Womack, D.S., Wickremashinghe, R., Wanigasuriya, K.P., Peiris-John, R.J., Lunyera, J., Smith, K., Raymer, J.H. and Levine, K.E., 2014. Additional perspectives on chronic kidney disease of unknown aetiology (CKDu) in Sri Lanka-lessons learned from the WHO CKDu population prevalence study, BMC nephrology 15(1), pp. 1-10.

17. Jayasekara, J.M., Dissanayake, D.M., Adhikari, S.B. and Bandara, P., 2013. Geographical distribution of chronic kidney disease of unknown origin in North Central Region of Sri Lanka. Ceylon Med J, 58(1), pp. 6-10.

18. Wanigasuriya, K., 2012. Aetiological factors of Chronic Kidney Disease in the North Central Province of Sri Lanka: A review of evidence to-date. 